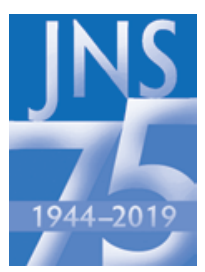

\title{
Treatment of adult thoracolumbar spinal deformity: past, present, and future
}

\author{
JNSPG 75th Anniversary Invited Review Article
}

\author{
Justin S. Smith, MD, PhD, ${ }^{1}$ Christopher I. Shaffrey, MD, ${ }^{2}$ Christopher P. Ames, MD, ${ }^{3}$ and \\ Lawrence G. Lenke, MD ${ }^{4}$
}

\begin{abstract}
1Department of Neurosurgery, University of Virginia Medical Center, Charlottesville, Virginia; ${ }^{2}$ Departments of Neurosurgery and Orthopaedic Surgery, Duke Medical Center, Durham, North Carolina; ${ }^{3}$ Department of Neurosurgery, University of California, San Francisco, California; and ${ }^{4}$ Department of Orthopaedic Surgery, Columbia University, New York, New York
\end{abstract}

\begin{abstract}
Care of the patient with adult spinal deformity (ASD) has evolved from being primarily supportive to now having the ability to directly treat and correct the spinal pathology. The focus of this narrative literature review is to briefly summarize the history of ASD treatment, discuss the current state of the art of ASD care with focus on surgical treatment and current challenges, and conclude with a discussion of potential developments related to ASD surgery.

In the past, care for ASD was primarily based on supportive measures, including braces and assistive devices, with few options for surgical treatments that were often deemed high risk and reserved for rare situations. Advances in anesthetic and critical care, surgical techniques, and instrumentation now enable almost routine surgery for many patients with ASD. Despite the advances, there are many remaining challenges currently impacting the care of ASD patients, including increasing numbers of elderly patients with greater comorbidities, high complication and reoperation rates, and high procedure cost without clearly demonstrated cost-effectiveness based on standard criteria. In addition, there remains considerable variability across multiple aspects of ASD surgery. For example, there is currently very limited ability to provide preoperative individualized counseling regarding optimal treatment approaches (e.g., operative vs nonoperative), complication risks with surgery, durability of surgery, and likelihood of achieving individualized patient goals and satisfaction. Despite the challenges associated with the current state-of-the-art ASD treatment, surgery continues to be a primary option, as multiple reports have demonstrated the potential for surgery to significantly improve pain and disability. The future of ASD care will likely include techniques and technologies to markedly reduce complication rates, including greater use of navigation and robotics, and a shift toward individualized medicine that enables improved counseling, preoperative planning, procedure safety, and patient satisfaction.
\end{abstract}

Advances in the care of ASD patients have been remarkable over the past few decades. The current state of the art enables almost routine surgical treatment for many types of ASD that have the potential to significantly improve pain and disability. However, significant challenges remain, including high complication rates, lack of demonstrated cost-effectiveness, and limited ability to meaningfully counsel patients preoperatively on an individual basis. The future of ASD surgery will require continued improvement of predictability, safety, and sustainability.

https://thejns.org/doi/abs/10.3171/2019.1.SPINE181494

KEYWORDS adult spinal deformity; complications; history; future; predictive analytics; robotics; surgery

$\mathrm{H}$ ISTORICALLY, care for adult spinal deformity (ASD) focused on supportive measures with few surgical options that were often deemed high risk. Improvements in anesthesia and critical care, surgical techniques, and instrumentation have led to remarkable advances in
ASD care over the last few decades. The population seeking ASD treatment continues to expand, as life expectancies increase and the desire to stay active into later life remains a priority.

Although care for ASD has evolved from supportive to

ABBREVIATIONS ASD = adult spinal deformity; CAT = computer adaptive testing; GSA = global sagittal alignment; ISSG = International Spine Study Group; LL = lumbar lordosis; MIS = minimally invasive surgery; PI = pelvic incidence; $\mathrm{PJK}=$ proximal junctional kyphosis; $\mathrm{PROM}=$ patient-reported outcomes measure; PROMIS = PatientReported Outcomes Measurement Information System; PSO = pedicle subtraction osteotomy; PT = pelvic tilt; RF = rod fracture; SVA = sagittal vertical axis; UIV = uppermost instrumented vertebra.

SUBMITTED December 27, 2018. ACCEPTED January 22, 2019.

INCLUDE WHEN CITING DOI: 10.3171/2019.1.SPINE181494. 
corrective, many challenges remain. Complication rates remain high, and data assessing the cost-effectiveness of these procedures are limited. As increasingly older patients with greater comorbidities seek ASD surgery, patient selection grows in complexity. Despite the challenges associated with the current state-of-the-art ASD treatment, surgery continues to be a primary option, as multiple reports have demonstrated the potential for surgery to significantly improve pain and disability. $5,76,80$

This narrative provides an overview of the history of ASD care, followed by discussion of current approaches and challenges associated with ASD treatment. The final section broadly describes several areas of potential future advances aimed to enhance care for ASD patients.

\section{Section 1: History of ASD Treatment}

Although the treatment of spinal deformity through nonoperative methods such as traction, external bracing, and casting has been utilized for many centuries, the true beginning of operative treatment dates back to the early 20th century. In 1911, Russell Hibbs introduced the concept of osseous fusion of thoracolumbar scoliosis, and his landmark publication in 1924 reported on this method of surgical treatment of 59 scoliosis patients. ${ }^{22}$ The method included exposure of the posterior elements over the area of deformity and partial removal of the facet joints, followed by decortication of the remaining posterior elements and placement of bone graft onto the decorticated surfaces for osseous union. The patient then was immobilized in a body cast, often kept non-weight bearing for several months postoperatively to limit spinal motion in order to optimize spinal fusion (Fig. 1). The goal was to maintain and not to correct the deformity, and complications, not surprisingly, were common. Amazingly, however, the basic tenets of performing and obtaining a posterior spinal fusion have continued to the present day, with major advances being made in the internal fixation applied simultaneously with the fusion procedure.

The start of spinal instrumentation to correct spinal deformities truly began with the revolutionary work of Paul Harrington. In the 1940s, the polio epidemic had left many unfortunate patients with debilitating spinal deformities and cardiopulmonary compromise who were not amenable to casting, bracing, or major fusion surgery treatment. Harrington initially tried to correct these types of scoliosis curves through the use of facet screws, which showed initial promise but poor long-term results. ${ }^{19} \mathrm{He}$ then worked on developing stainless steel rods and hooks of sufficient strength to withstand the forces involved to both apply corrective distractive forces to the spine and support the loads when upright. This then afforded some correction of the deformity along with enough stabilization to avoid prolonged recumbency and shortened external immobilization usage and time. Initially, Harrington did not perform a fusion procedure, and the implants not surprisingly dislodged or broke routinely. Harrington then was convinced by John Moe, who worked in Minneapolis, to add a fusion to the Harrington instrumentation procedures, and the results were exceedingly better. ${ }^{45}$ However, over time, limitations to the sin-

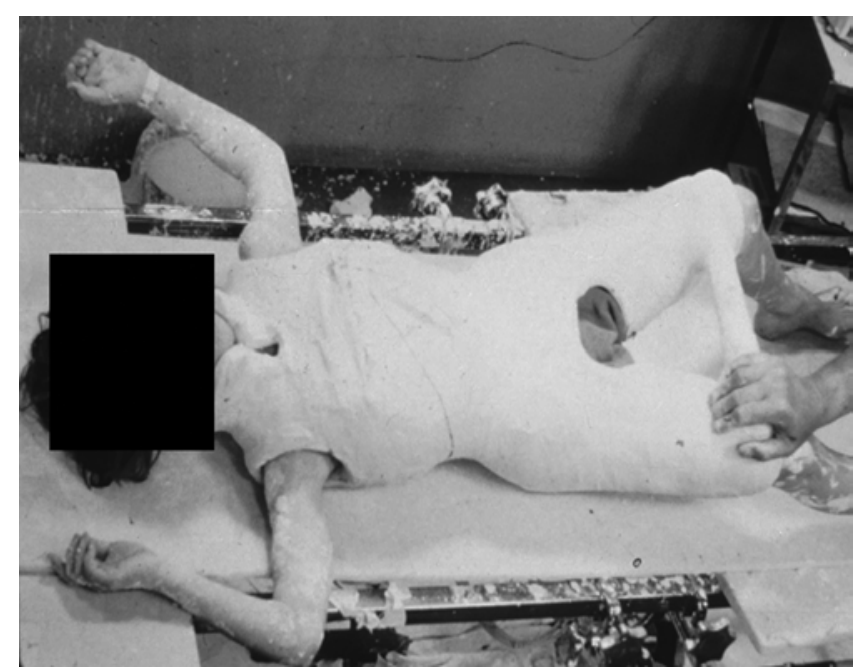

FIG. 1. Postoperative photograph of a patient who underwent a posterior spinal fusion in situ for an idiopathic scoliosis deformity in the 1950s. The patient is immobilized from the neck to the lower extremities in a total body cast as external means to help gain a solid spinal fusion. Courtesy of Department of Orthopaedic Surgery, Shriners Hospital for Children, St. Louis, Missouri.

gle-rod/2-distraction-hook Harrington device became evident, including difficulty obtaining solid fusion when extending into the low lumbar spine, dislodgment of the distal hook with constructs extending to the sacrum, and the universal loss of lumbar lordosis (LL) with concave lumbar distraction. The consequences of this last limitation, really a result of a lack of sagittal plane analysis or understanding, remain a common indication for surgical revision for flat back conditions even in current practice (Fig. 2). ${ }^{37}$

The next evolution of ASD treatment involved entering the age of segmental spinal instrumentation as initially espoused by Eduardo Luque. He developed Luque instrumentation that included placing bilateral sublaminar wires at each level, then fixing them to rods applied on each side of the posterior elements. ${ }^{41}$ This created a much more stable construct with the additional fixation points that usually obviated any postoperative immobilization. However, the passing of sublaminar wires, which rested on the dorsal dural surface, led to reports of neurological compromise that caused concern for many surgeons using this technique. ${ }^{92}$ Nevertheless, the beneficial concept of segmental instrumentation had begun and exists today. Surgeons also began combining the Harrington rod concept with the segmental Luque wires, which became referred to as the Harri-Luque technique, which entailed placing segmental sublaminar wires and wrapping those around the single Harrington rod.

Another key component to the early days of segmental spinal fixation for spinal deformity came through placement of spinal instrumentation via the anterior route. In the 1960s, Dwyer and colleagues reported using anterior vertebral body screws and plates on the convexity of scoliosis curves in the thoracolumbar and lumbar spine, then placing a threaded cable that was compressed to shorten the anterior column and correct the scoliosis curve. ${ }^{12}$ This 

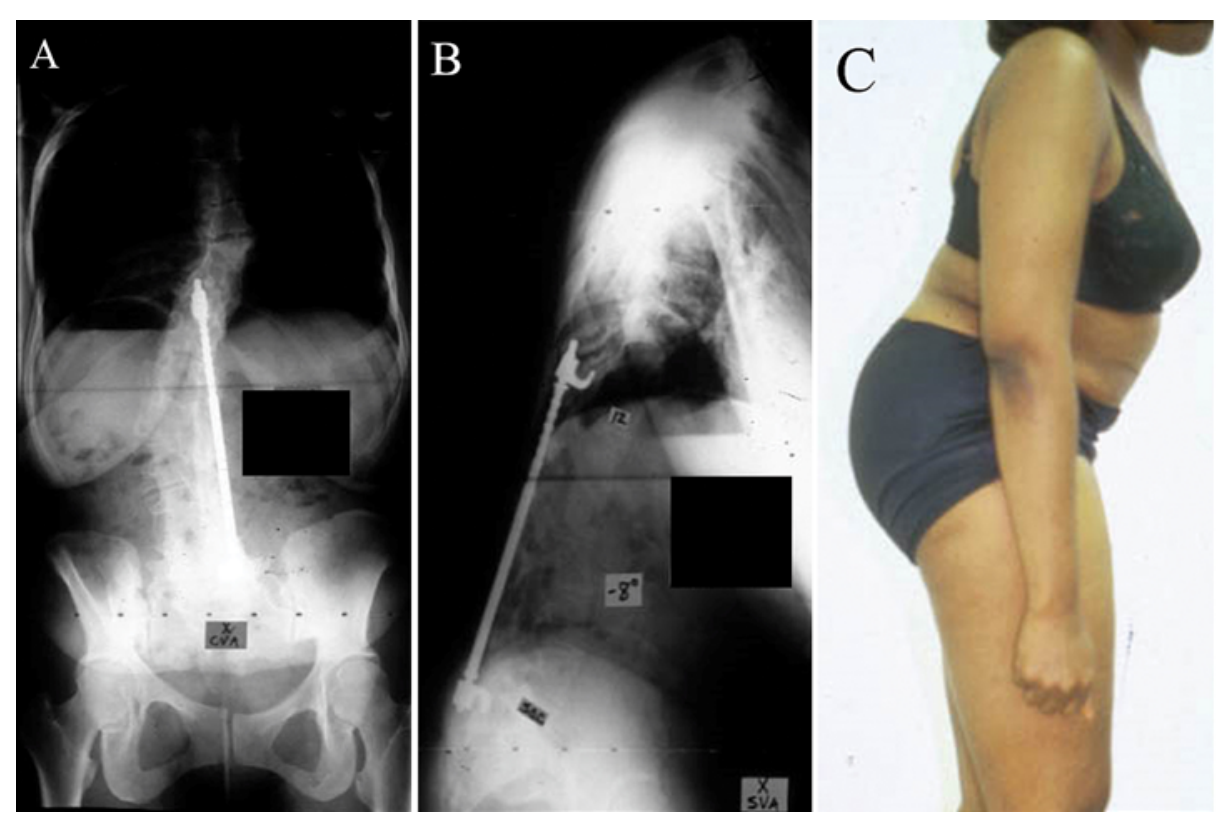

FIG. 2. Photograph of a patient with a lumbar idiopathic scoliosis who underwent a Harrington rod instrumentation and lumbar fusion for her deformity in the 1970s. She did well for many years, but presented 20 years postoperatively with a flat back syndrome due to loss of LL produced by the distraction of the lumbar spine. Figure is available in color online only.

technique was modified and the cable replaced with a threaded rod by Klaus Zielke, and this device became very popular for anterior correction of scoliosis beginning in the 1970s until the turn of the century. Both of these early devices utilized small cables or rods and thus spinal stability, performed by an anterior discectomy and fusion that was performed along with the instrumentation, required postoperative bracing or casting. ${ }^{95}$ Another limitation was that the convex compression of the mid- and lower-lumbar spine was kyphogenic, which created iatrogenic flat back deformities similar to those produced by posterior Harrington distraction instrumentation.

The dawn of "modern" spinal instrumentation is attributed to Yves Cotrel and Jean Dubousset, who created the posterior instrumentation and also the correction philosophy behind segmental dual rod constructs initially using all hook implants. As first reported in 1988, Cotrel-Dubousset instrumentation revolutionized the treatment by allowing for increased spinal stability afforded by multiple hooks placed at strategic locations on both sides of the spine, connected by knurled rods placed bilaterally and cross-linked by devices for transverse traction. ${ }^{11}$ This stable construct obviated postoperative bracing, and the corrective maneuvers, including the rod rotation, afforded unparalleled deformity correction in children and adults and quickly became the standard for spinal deformity specialists around the world with this device or many other "clone" devices that mimicked this type of dual segmental instrumentation system. Ultimately, screws have slowly replaced hooks as the main implant due to their 3-column purchase of the vertebra, which allows segmental stability and correction ability far beyond what segmental hooks can produce. ${ }^{18}$ By 2000 , segmental pedicle screw fixation had become the most commonly utilized construct for ASD surgery and remains so today.

\section{Section 2: Current State of the Art for ASD Treatment and Remaining Challenges Patient Presentation and Management Decisions \\ Prevalence of ASD and Clinical Presentation}

Many developed countries, including the United States, are experiencing an unprecedented shift toward an aging population. With an expanding elderly population, it will be necessary to increasingly address its medical needs. Although spinal deformity has impact across all ages, it disproportionately affects the elderly. Schwab and colleagues reported a $68 \%$ prevalence of scoliosis in volunteers older than 60 years. ${ }^{68}$

Spinal deformity is a heterogeneous condition that can have varying impact depending on type and severity. While the finding of spinal deformity may be incidental, other cases may present with significant pain and disability. Two studies have shown that ASD can have debilitating impact on health that exceeds that of other chronic disease states, including heart disease, lung disease, and limited use of arms and legs. ${ }^{4,54}$

\section{Maximizing Nonoperative Treatments}

In the absence of significant or progressive neurological deficit or rapidly worsening deformity, nonoperative treatment approaches should be maximized. Glassman and colleagues documented the substantial costs of nonoperative treatments but found no mean improvement in health status. ${ }^{16}$ Although other studies have also shown no mean improvement in health status with nonoperative treatments, ${ }^{5,6,30,76-78,86}$ there are subsets of patients that may benefit. $^{76}$ Attempts to define which patients may benefit most from nonoperative treatment have provided only limited insight, and the longer-term durability of these treatments is unclear. ${ }^{40,73}$ 


\section{Selection and Counseling of Patients for Operative Treatment}

A growing amount of literature supports the potential of surgical treatment for ASD to significantly improve pain and disability. ${ }^{5,6,30,76-78,80,83}$ However, these procedures are associated with high complication rates. Based on a risk-benefit assessment of ASD surgery with age stratification, Smith and colleagues noted that older patients had the worst pain and disability at baseline.$^{80}$ At 2 years after surgery, the elderly, despite facing the greatest risk of complications, had a disproportionately greater improvement in disability and pain. ${ }^{80}$

When contemplating surgical treatment for ASD, counseling should take into account individual patient expectations. ${ }^{61}$ An extensively fused spine may provide improvement in pain and disability but results in greater stiffness and may produce new limitations. ${ }^{20}$ In addition, not all patients can be expected to meet reported mean outcome improvements; instead, outcomes span a broad range. ${ }^{81}$

\section{Radiographic Assessment and Surgical Planning}

Radiographic Measurements of Spinopelvic Alignment

Historically, assessment of ASD focused on the coronal plane, but the importance of the sagittal plane has been increasingly recognized. ${ }^{2}$ Glassman and colleagues were among the first to demonstrate the relationship between global sagittal alignment (GSA) and health-related quality of life. ${ }^{15}$ Subsequent studies have confirmed this relationship and defined the importance of pelvic morphology and alignment. ${ }^{70}$

Global coronal alignment and GSA can be assessed based on standing full-length spine radiographs (Fig. 3A and B). GSA can be expressed as the sagittal vertical axis (SVA; Fig. 3B). Alternatively, thoracic spinopelvic inclination (Fig. 3B) or novel measures, such as the T1 pelvic angle, ${ }^{55}$ can be used to quantify GSA. Basic regional measures of sagittal alignment include thoracic kyphosis and LL (Fig. 3C).

Evaluation of the key pelvic parameters, pelvic incidence (PI) and pelvic tilt (PT), adds context to the assessment of spinal alignment (Fig. 3D).$^{70} \mathrm{PI}$ is a morphological parameter that reflects the relationship between the sacrum and femoral heads and establishes the amount of LL needed by an individual. PT reflects the degree of pelvic retroversion, which is a compensatory measure for GSA. Although an important compensatory mechanism, excessive PT can be a source of pain and disability. ${ }^{70}$

Based on correlations between radiographic alignment parameters and health-related quality of life measures, Schwab and colleagues developed the Scoliosis Research Society-Schwab classification for ASD (Fig. 4) ${ }^{69,75}$ Although this classification has recognized limitations, including its sole basis on radiographic assessment and its lack of accounting for age, ${ }^{36}$ it serves as a starting point and remains the most widely applied ASD classification.

\section{Surgical Planning Software}

Accurate radiographic assessment is important for evaluating ASD patients clinically and for surgical planning. Detailed radiographic measurements can be time consuming, prompting a growing interest in automation. For exam- ple, a new computer-assisted tool to measure spinopelvic parameters has been reported in which users outline basic spine structures. ${ }^{33}$ The software then automatically calculates spinopelvic parameters.

\section{Surgical Techniques and Approaches}

Current surgical techniques for ASD are heavily based on posterior instrumentation, interbody releases and fusions, and osteotomies (Fig. 5). ${ }^{76,83}$ Schwab and colleagues reported a comprehensive anatomical spinal osteotomy classification for thoracolumbar deformities. ${ }^{67}$ In addition, some surgeons also employ lateral and anterior discectomies to aid in deformity correction and arthrodesis. ${ }^{51}$

Currently, surgeons use a number of techniques for pedicle screw placement, including freehand, fluoroscopyassisted, navigation-assisted, and, at the leading edge of innovation, robot-assisted. Whether one technique is superior remains unclear. ${ }^{72,88}$

\section{Strategies to Reduce Complications and Improve Safety}

Smith and colleagues reported a prospective assessment of complications among 346 surgically treated ASD patients with 2-year follow-up..$^{74}$ Approximately $70 \%$ of patients experienced at least 1 complication, and $28 \%$ required at least 1 revision procedure. The most common complication categories included implant-related, radiographic, neurological, operative, cardiopulmonary, and infection. Efforts to better understand and reduce complications with ASD surgery are ongoing priorities.

\section{Pseudarthrosis and Instrumentation Failure}

Pseudarthrosis and instrumentation failure remain common indications for revision surgery. ${ }^{52,74,82}$ Based on a prospective series of ASD patients, the overall rod fracture (RF) rate was 9\%. ${ }^{82}$ Among the patients treated with a pedicle subtraction osteotomy (PSO), the RF rate was $22 \%$, with almost all occurring at the PSO site. Many of these RFs occurred earlier than fusion would be expected, suggesting that biomechanical compromise of the rods may have contributed to failure.

Tang and colleagues demonstrated that greater angular bending of rods, such as that occurring across a PSO, significantly reduced rod fatigue life. ${ }^{85}$ This finding, in combination with the high rates of RFs across PSOs, has led many surgeons to use additional rods to span osteotomy levels. Multiple rod configurations have been described (Fig. 6). Accessory rods are attached directly to primary rods with side-to-side connectors. Satellite rods attach independently to the vertebral levels adjacent to the PSO, thereby reducing the angular bend necessary in the primary rods and the rate of RF. ${ }^{17}$

Strategies to reinforce implants with additional rods appear to be helpful; however, unless fusion occurs, additional metal may simply delay RF. Although costly and off-label for most spine applications, recombinant human BMP-2 does appear to be effective in promoting bony fusion in ASD surgery. ${ }^{31,53}$

\section{Proximal Junctional Kyphosis/Proximal Junctional Failure}

Proximal junctional kyphosis (PJK) arguably remains 
A

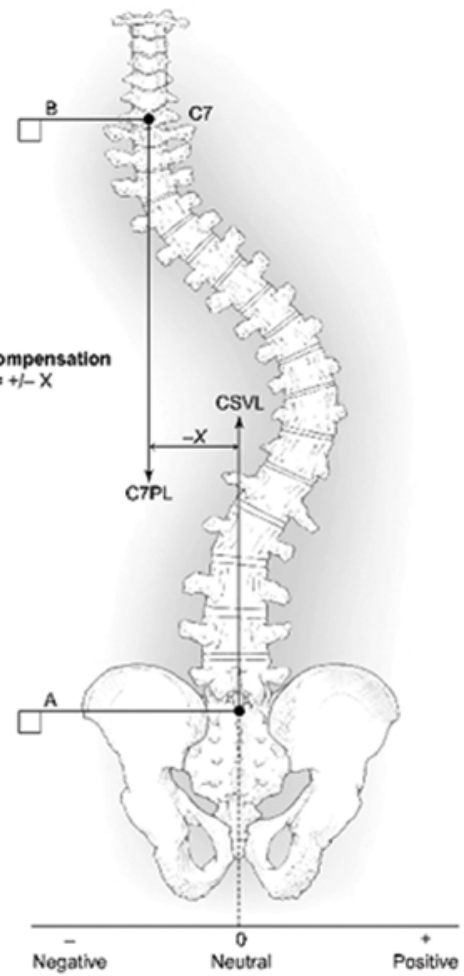

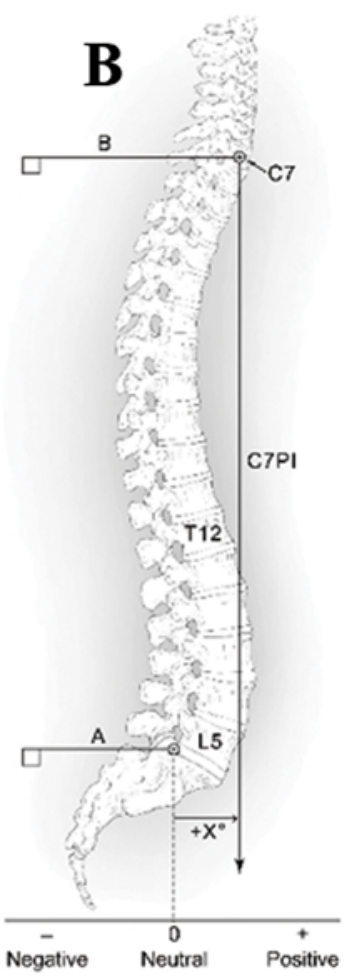

C

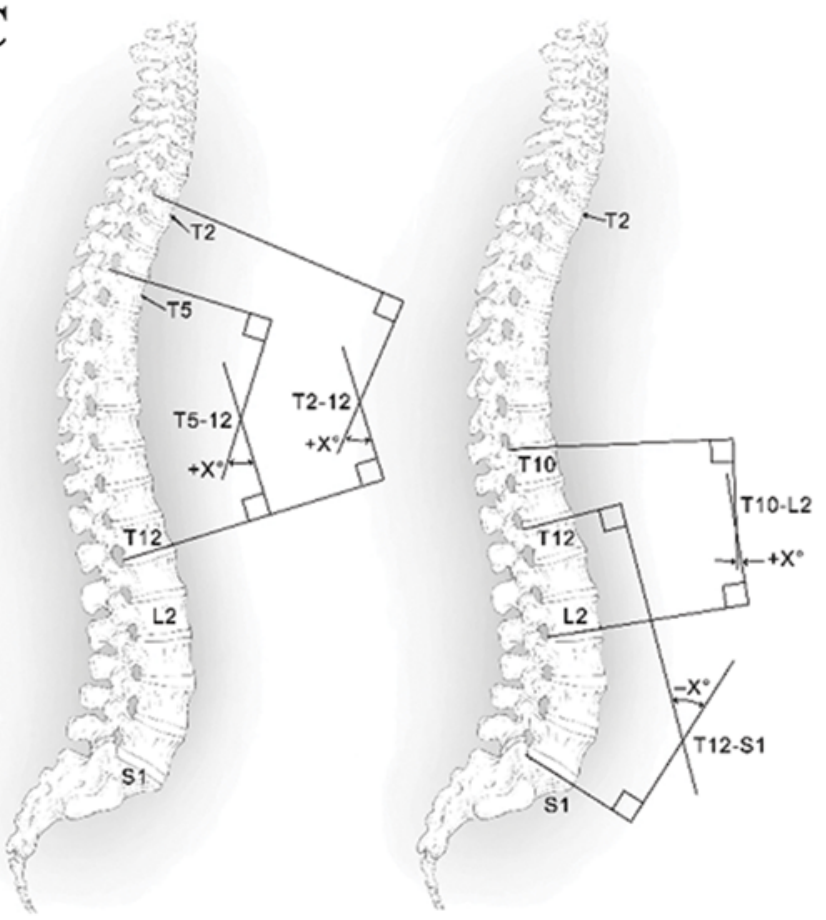

D

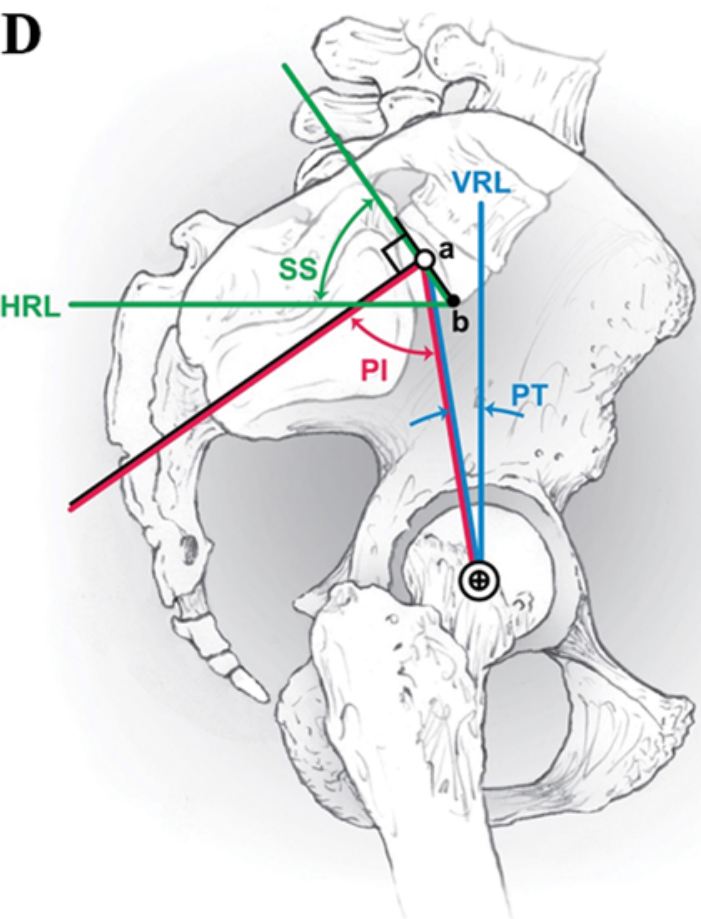

FIG. 3. Illustrations of radiographic spinopelvic parameters. A: Diagram showing the measurement of global coronal alignment (-X). B: Diagrams showing 2 techniques for assessment of GSA, including SVA (+X, left) and T1 and T9 spinopelvic inclination (right). C: Illustrations of regional measures of thoracic kyphosis (+X, left), thoracolumbar sagittal angle (T10-L2 [+X], right), and LL (T12-S1 [-X], right). D: Pelvic radiographic parameters, including sacral slope (SS), PT, and PI. CSVL = central sacral vertical line; $\mathrm{HRL}=$ horizontal reference line; $\mathrm{PL}$ = plumb line; $\mathrm{VRL}$ = vertical reference line. Copyright Kenneth X. Probst. Published with permission from XavierStudio. Figure is available in color online only. 
the greatest unsolved problem in ASD surgery and can require major revision surgery. ${ }^{30,58,74}$ Multiple recent reports have helped to further the understanding of PJK and provided steps to potentially reduce its occurrence. The Hart-International Spine Study Group (ISSG) PJK severity scale can help identify which PJK patients may need revision surgery. ${ }^{38}$

Bony fracture at the proximal junction is a common mechanism of failure that is likely related to bone density. Few studies have directly addressed the relationship between bone density and junctional failure. Yagi and colleagues reported on the effectiveness of teriparatide as a protective treatment for junctional fracture following ASD surgery in women with osteoporosis or osteopenia. ${ }^{93}$

Although their clinical effectiveness remains under investigation, junctional tethers are an emerging technique with potential to reduce PJK risk (Fig. 7). A finite element analysis by Bess and colleagues suggested that tethers are effective in dissipating the forces at the uppermost instrumented vertebra (UIV), ${ }^{3}$ and recent case series support their clinical effectiveness in reducing PJK. ${ }^{7,8}$

The magnitude and location of correction of LL also appear to be important factors in PJK development. It is important to apply age-adjusted alignment objectives when planning ASD surgery to reduce the risk of overcorrection of LL, which may produce excessive compensatory junctional kyphosis. ${ }^{36,62}$ Although historically L3 has been the most common level for lordosis restoration via PSO, emerging evidence suggests that restoring lordosis in a more physiological location (i.e., L4-S1) may be protective against PJK. ${ }^{35}$

Orientation of the UIV and terminal rod contouring also appear to be important factors in PJK development. Lafage and colleagues reported significant differences in UIV angulation between patients who did and did not develop PJK. ${ }^{34}$ Their findings reinforce the importance of preoperative planning, careful UIV selection, and proper rod contouring to reduce PJK.

\section{Wound Infection}

Wound infection after ASD surgery is a potentially serious complication that may necessitate reoperation and prolonged antibiotic treatment and can increase the risk of pseudarthrosis. Although off-label, application of vancomycin powder directly into the wound following ASD surgery has been used by some surgeons as a means of reducing postoperative wound infections. Several studies suggest its potential effectiveness; however, additional higher-level evidence is warranted. ${ }^{87,94}$

\section{Excessive Blood Loss}

Although an effective anesthesia team can readily replace blood, significant blood loss can lead to complications. Recent studies have suggested that antifibrinolytics have the potential to reduce intraoperative and postoperative blood loss. ${ }^{10}$ The most commonly studied of these is tranexamic acid (TXA), a synthetic lysine analog that inhibits fibrinolysis. ${ }^{10}$ Optimal dosing of TXA remains unclear, and contraindications and relative contraindications should be assessed, including history of deep venous

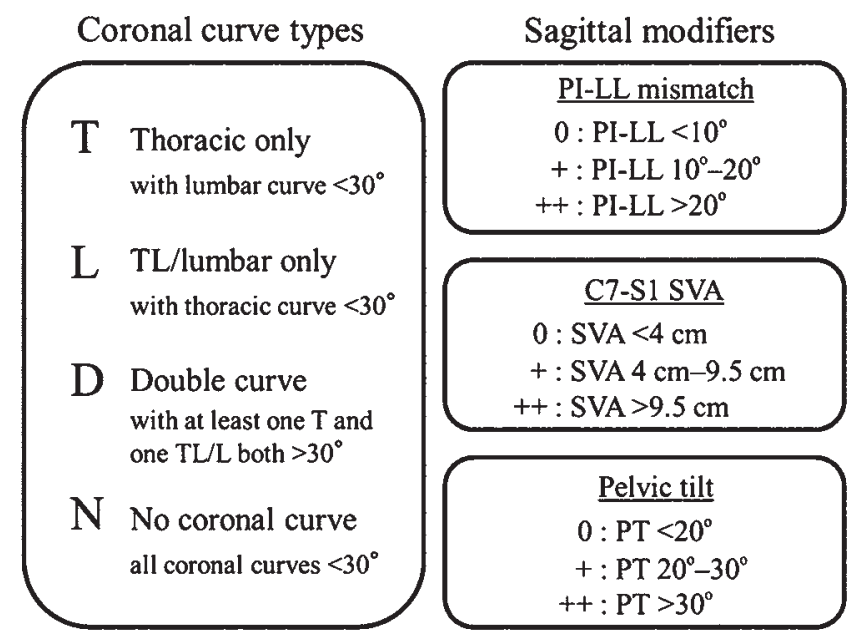

FIG. 4. Schematic of the Scoliosis Research Society-Schwab classification for adult thoracolumbar spinal deformity redrawn from Schwab et al. ${ }^{69} \mathrm{PI}-\mathrm{LL}=\mathrm{PI}$ to LL mismatch; TL = thoracolumbar.

thrombosis, pulmonary embolism, stroke, myocardial infarction, and cardiac stenting.

Rotational thromboelastometry (ROTEM) is a functional viscoelastic assay for real-time assessment of coagulation abnormalities..$^{48}$ Intraoperative use of ROTEM can facilitate standardization of transfusion practices and enable early identification and treatment of hypofibrinogenemia. Naik and colleagues recently reported its application to major spine surgery and found that its use resulted in decreased blood loss, reduced transfusion requirements, and lower cost. ${ }^{48}$

\section{Neurological Deficits}

Neurological deficits are among the most potentially impactful of complications associated with ASD surgery. To better define the incidences and severities of new neurological deficits in surgically treated ASD patients $(75 \%$ having a 3-column osteotomy), Lenke and colleagues prospectively assessed neurological outcomes using the American Spinal Injury Association lower extremity motor score (LEMS). ${ }^{39}$ They reported a decline in LEMS in $22.18 \%$ of patients at the time of hospital discharge, compared with $12.78 \%$ of patients who showed an improvement. At 6-month follow-up, $10.82 \%$ of patients had an overall decline in LEMS compared with preoperative scores, and $20.52 \%$ and $68.66 \%$ had improvement and maintenance of scores, respectively. These data provide a basis for surgical planning, counseling, and efforts to prevent or treat these events.

\section{Evolving Role of Minimally Invasive Approaches \\ Current Applications and Algorithms}

There is growing interest in spinal minimally invasive surgery (MIS) techniques for ASD with the goal of reducing morbidity, complications, and recovery time. ${ }^{51,91}$ Two basic MIS approaches have been most commonly reported..$^{51,91}$ The circumferential MIS technique includes a lateral approach for discectomies, followed by posterior percu- 

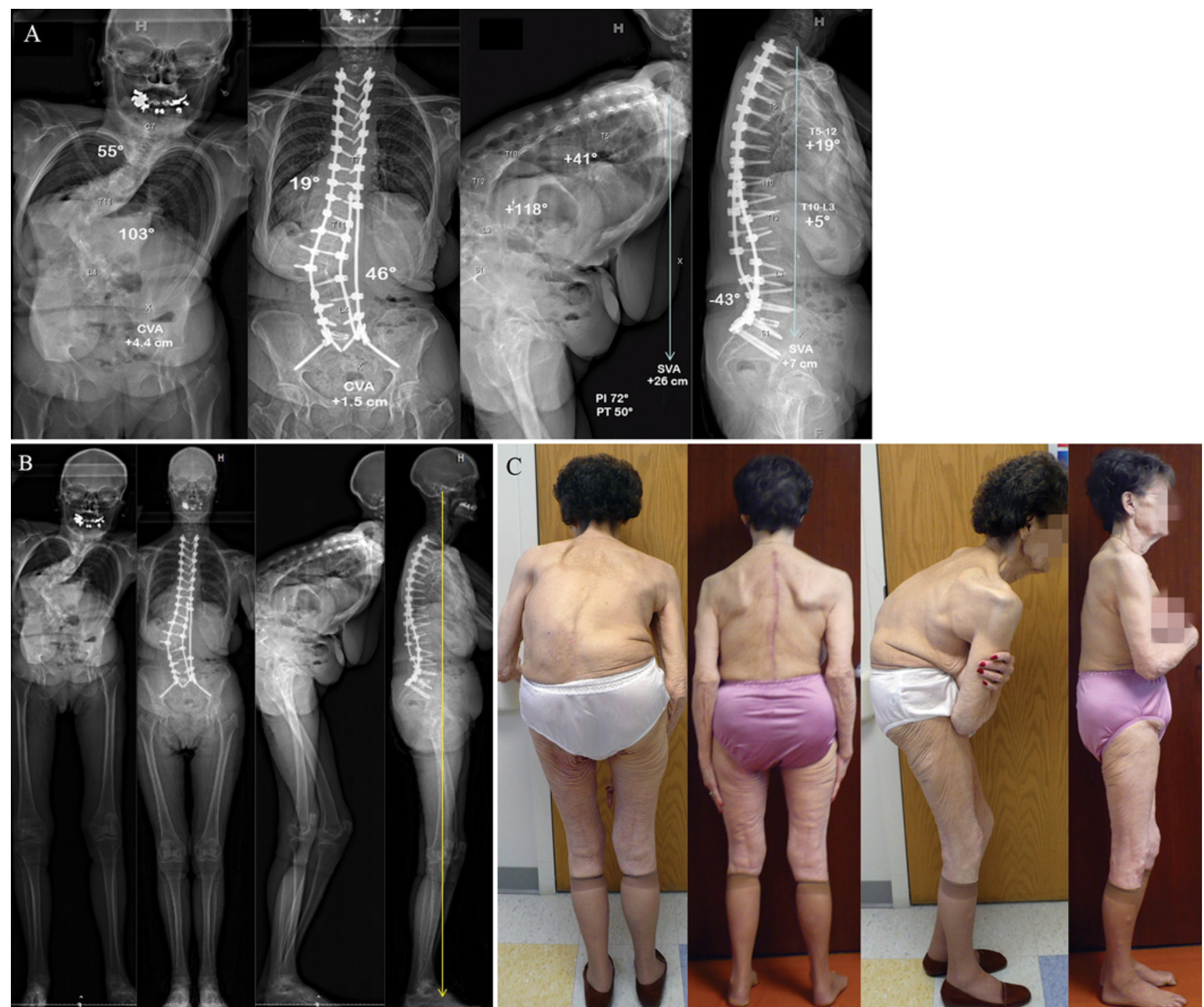

FIG. 5. This is a 69 -year-old woman with a longstanding idiopathic thoracolumbar kyphoscoliosis who had progressive deformity with aging. The patient presented with a severe spinal deformity that led to progressive coronal and sagittal plane malalignment. She had no prior history of spinal surgery and complained of truncal pain and worsening posture. A: The patient underwent an allposterior spinal reconstruction from T2 to the sacrum/ilium with posterior column osteotomies from T11 to L4 and a transforaminal lumbar interbody fusion at L5-S1 with a structural cage. Correction of her deformity was accomplished with optimal intraoperative positioning, secure segmental pedicle screw fixation, then cantilever, segmental compression/distraction and in situ rod contouring using a 3-rod technique with the third rod extending from the thoracolumbar junction to the lumbosacral junction. Posterior fusion was performed with local autograft, allograft, and BMP-2. B: Preoperative and postoperative total body images demonstrating the total body realignment after the spinal reconstruction with improved global coronal and sagittal plane posture. The ability to analyze our patient's entire skeleton allows for quantification of the compensatory changes that occur both within the unfused spine and to the lower extremities as well as both prior to and following spinal deformity surgery. C: Preoperative and postoperative photographs showing the improved posture obtained after this spinal reconstruction without any postoperative complications noted. Figure is available in color online only.

taneous instrumentation. In contrast, the hybrid approach combines lateral discectomies with a traditional posterior open approach for osteotomies and instrumented fusion.

As a means of addressing sagittal malalignment through a minimally invasive lateral approach, the anterior column release has been introduced in which the anterior longitudinal ligament is released at an open disc space level. ${ }^{89} \mathrm{In}$ addition, Wang and Bordon have described an MIS PSO technique in which the procedure is performed using MIS techniques except for the spinal levels immediately adjacent to the PSO. ${ }^{90}$

Patient selection for MIS ASD treatment remains a challenge. ${ }^{13}$ The MIS deformity (MISDEF) surgery algorithm was created to provide a framework for decision making. ${ }^{47}$ Based on preoperative radiographic parameters, this algorithm leads to one of 3 general plans that range from MIS direct or indirect decompression to open deformity surgery with osteotomies. 

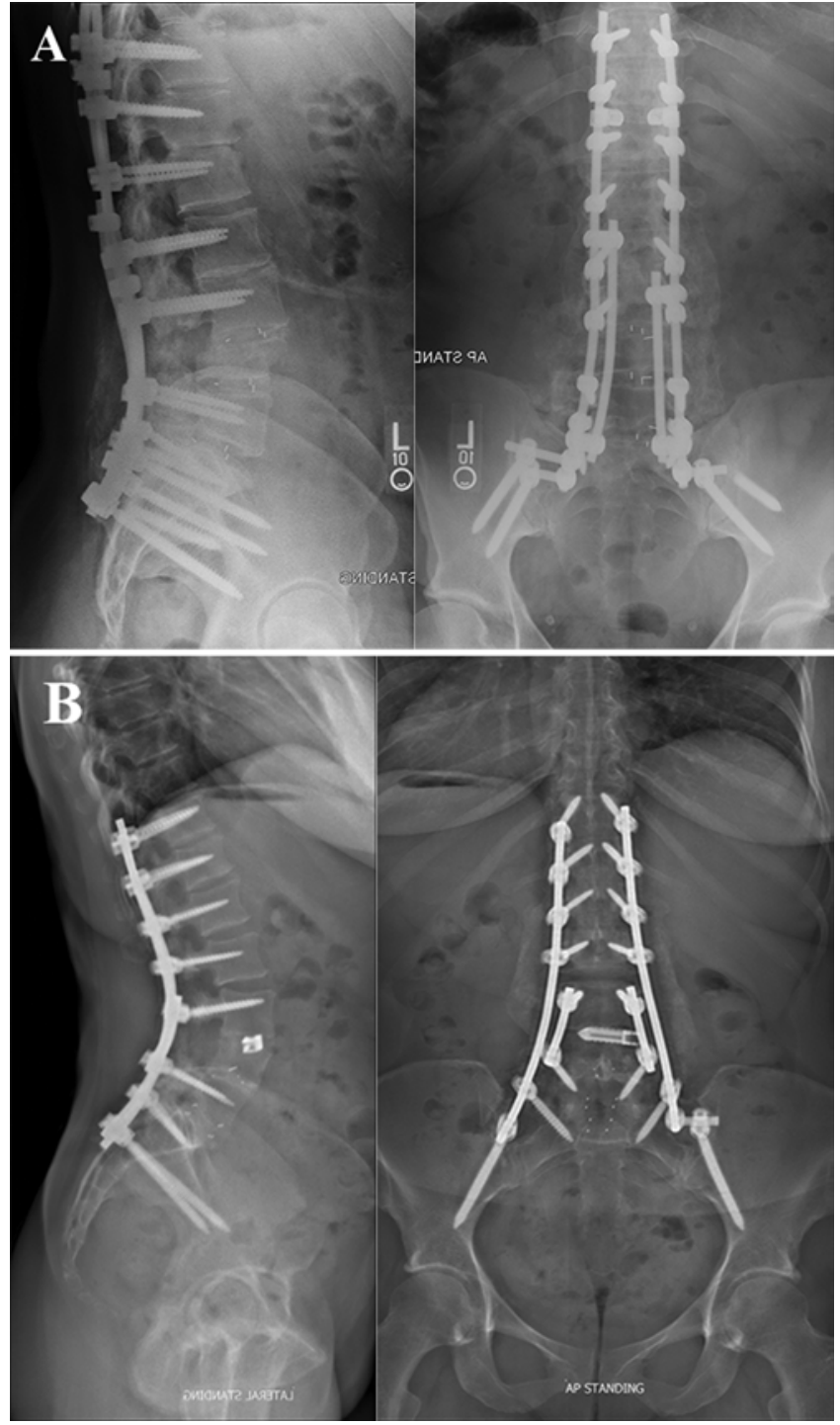

FIG. 6. Examples of multirod configurations for PSO. A: Lateral (left) and posteroanterior (right) radiographs obtained after an extended L4 PSO (Schwab type 4). The construct includes right and left accessory rods (directly connected to the primary rods) that bridge the levels of the PSO. Note the retained fractured iliac screw on the right side from a previous surgery. B: Lateral (left) and posteroanterior (right) radiographs obtained after an extended L4 PSO (Schwab type 4). The construct includes right and left satellite rods (rods spanning the PSO levels and not connected to the primary rods).

\section{Complications and Outcomes Assessments}

As MIS approaches are applied to ASD, the associated limitations and complications have become increasingly clear. ${ }^{27}$ Some complications are similar to those of open procedures, including PJK and pseudarthrosis. ${ }^{27,46,74}$ Other complications directly relate to the MIS lateral approach, including neurological injuries, abdominal wall paresis, bowel perforation, lateral incisional hernia, and graft subsidence. $^{27}$

Few reports have provided assessment of clinical outcomes for MIS ASD treatment, and those available are limited by a number of factors, including inadequate follow-up length and rates, retrospective design, lack of objec- tive outcomes measures, and lack of an appropriate comparison group..$^{13,51,90}$ Further study is needed to explore radiographic and clinical outcomes for MIS ASD treatment.

\section{Patient-Reported Outcomes Measures}

Patient-reported outcomes measures (PROMs) can be used to assess disease impact and treatment effectiveness and can be divided into those that are general health measures and those that are disease specific. General health measures, including the SF-36 and the EQ5D, can be used to assess disease impact and enable comparisons across other disease states. ${ }^{4,54}$ Disease-specific outcomes measures commonly applied to ASD include the Scoliosis Research Society questionnaires and the Oswestry Disability Index.

The National Institutes of Health developed the PatientReported Outcomes Measurement Information System (PROMIS) as a means of unifying clinical outcomes-based research. The goal of PROMIS is to utilize a large bank of questions that could apply to all disease states in order to serve as a single standard PROM. PROMIS questions address 3 health categories (physical, mental, and social health) and a global health category. The PROMIS questionnaire can be administered in static form or using computer adaptive testing (CAT). With CAT, how an individual respondent answers a question determines which questions follow and may significantly reduce the number of subsequent irrelevant questions. ${ }^{25,26}$ Although few studies have explored the use of PROMIS in spine surgery, those available are supportive of its validity and responsiveness. ${ }^{56}$

\section{Current Challenges}

Interest in ASD treatment has rapidly expanded over the last couple of decades and considerable advances have been made, ${ }^{79}$ but many challenges remain. As the demographic in many developed countries shifts to an older population, the numbers of elderly seeking care for ASD will continue to expand. Despite often being among the most impacted by their ASD ${ }^{80}$ these patients tend to have greater comorbidities and overall frailty, ${ }^{44,57}$ adding to the already complex decisions surrounding risk-benefit assessments of surgery, patient optimization, and challenges of what the current state of the art can reasonably offer.

It is unlikely that ASD surgeries will ever be free from risk. However, there is a need to reduce the current rates of complications and reoperation rates for ASD surgery, which have been reported as $70 \%$ and $28 \%$, respectively, at the 2-year follow-up..$^{74}$ Although considerable advances continue to be made,$^{79}$ improving the safety and durability of ASD surgery must remain a critical focus.

ASD surgeries are among the most costly of spine surgeries, and demonstrating the cost-effectiveness of these procedures remains a challenge. ${ }^{43}$ Although substantial resources are consumed upfront with ASD surgery, the potential for benefits to be extrapolated over many years may demonstrate cost-effectiveness. However, high reoperation rates can erode the cost-effectiveness of these procedures. ${ }^{43}$ Further research is needed to better understand the costs of ASD surgery and how to maximize durability.

There remains considerable variability across multiple aspects of ASD surgery. Although patients on average demonstrate significant improvement in pain and disabil- 


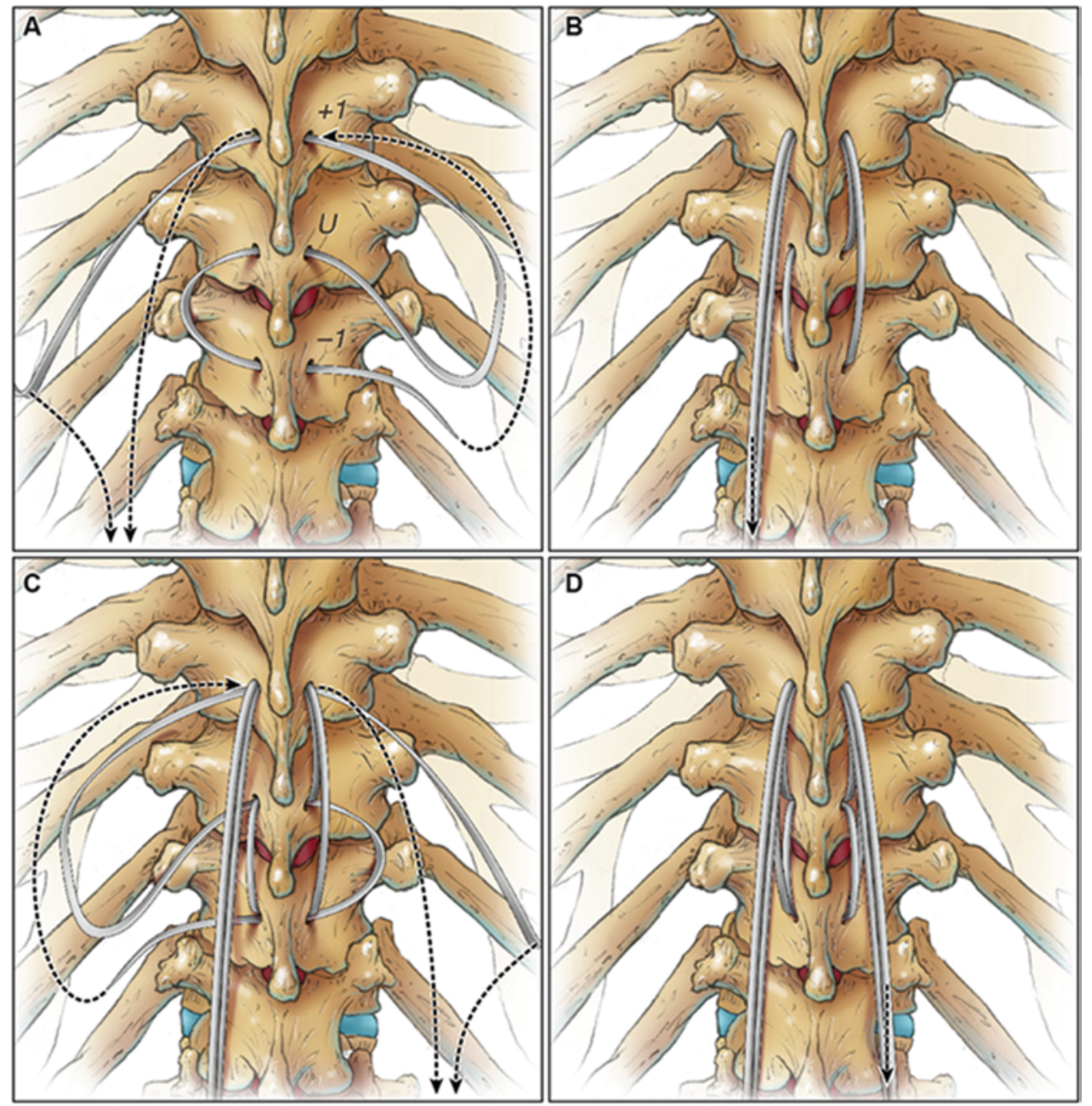

FIG. 7. Illustrations depicting a technique for proximal junctional tethering. A high-speed drill is used to create holes through the base of the spinous process at the UIV $(U)$ and through the vertebral levels above $(+1)$ and below $(-1)$ this level. The tether is then threaded through these levels (A) and pulled securely on one side (B). The other end of the tether is threaded in an opposite pattern through the same vertebral levels (C), and this end is cinched (D) on the opposite side. The tether ends are then tightly secured to the rods via cross-link or through specially designed lateral connectors that attach to the rods. Copyright Kenneth $X$. Probst. Published with permission from XavierStudio. Figure is available in color online only.

ity with surgery, $6,30,76$ the spectrum of outcomes is broad and it can be difficult to predict which patients may benefit most from surgery. ${ }^{81}$ Overall complication rates have been documented for ASD surgery, but the risk of complications and their potential impact remain difficult to predict for an individual patient. The costs associated with ASD surgery are substantial and can be variable and difficult to predict. The ability to address the many marked variabilities associated with ASD surgery is a significant challenge.

\section{Section 3: The Future of ASD Treatment: Improving Predictability, Safety, and Sustainability}

\section{The Future Role of Surgery for ASD}

Role of Multidisciplinary Panels and Payers in Controlling Access to Surgical Care

Annual healthcare spending in the United States currently consumes $17.9 \%$ of gross domestic product and is expected to reach $\$ 5.7$ trillion by $2026 .{ }^{9}$ There will no doubt be continued intense downward pressure on healthcare spending well into the future. A burgeoning elderly population, coupled with increasing utilization and high costs of surgical treatment for ASD, may create an environment ripe for limiting access to care.

Broader utilization of bundled payment and population health programs tend to favor what are perceived as less costly nonoperative treatments ${ }^{60}$ despite limited evidence of the benefit in patients who are surgical candidates. ${ }^{6,16,74}$ Although multidisciplinary panels may be a means of reducing complication risk, ${ }^{71}$ such panels could easily be used to limit care to those who may stand to benefit the most, especially at centers incentivized with bundled payment or population health contracts. It is important for those who provide care to ASD patients to ensure their future access to surgical options.

\section{Are More Effective Nonoperative Treatments on the Horizon?}

While it is possible that future advances in nonopera- 
tive care for ASD could markedly reduce the need for surgical treatment, such a development is unlikely in the near term. In addition, the symptoms and disability directly related to global and regional spinal malalignment could be challenging to effectively treat nonoperatively. However, a variety of treatment approaches could have at least theoretical benefit to ASD patients with primary complaints of back or leg pain. For example, with continued advances in the understanding of central pain control, it is conceivable that some combination of cortical, spinal, and peripheral stimulation could sufficiently reduce symptoms for a subset of ASD patients. ${ }^{21,23,29}$

\section{Robotics and Navigation}

\section{What Are the Limits to What Robots Can Do?}

The application of robots to spine surgery has been heavily driven by the dependence of MIS surgeons on navigation techniques and a desire to reduce radiation exposure and increase precision. Early applications of robotics to spine surgery have predominantly focused on placement of pedicle screws, and for this task robots appear to have an acceptable level of accuracy on a consistent basis. ${ }^{14}$ Currently, robots are confined to aiding in establishing a trajectory based on navigation, with actual pedicle screw placement left to the surgeon.

Robots have the potential for much more. Madhavan and colleagues envision a semiautomated device with integrated scanners and surgical arms or even a fully operational humanoid machine, but readily acknowledge that these remain fantasies at present. ${ }^{42}$ They note that more likely near-term advances will take the form of semiindependent machines attached to the operative table and having robotic arms that can place percutaneous screw-androd systems. The surgeon may be equipped with a headset and visor to enable an augmented reality overlay and the ability to alter and/or command the robotic arms through voice commands or sensor gloves. ${ }^{42}$ In addition, MRIbased navigation could enable robot assistance with disc work and tumor resection and provide safer cues for robot assistance with osteotomies and bony decompression..$^{50}$

\section{Role of the Surgeon in the Age of the Robot}

Will the march toward robotics obviate the need for surgeons? Although much of spine surgery is complex carpentry, the materials are highly heterogeneous and the consequences high. Robotic applications to spine surgery should be viewed as tools that the surgeon may use to potentially augment the safety of procedures, especially for minimally invasive approaches and for patients with challenging anatomy. For the foreseeable future and likely generations to come, the role of and need for the surgeon appear to be secure.

\section{Advances to Further Reduce Complications}

Complication rates remain high in ASD surgery. RF is the most common instrumentation failure. Although advances are being made through various multirod configurations ${ }_{17}^{17}$ it remains unclear whether additional rods may simply delay RF. Improved means of rod contouring are needed, and the recent introduction of preplanned ma- chine-bent rods may improve fatigue life, thereby extending the time for arthrodesis to occur. ${ }^{84}$ In addition, preplanned rods may facilitate achievement of desired spinal alignment which may also enhance fatigue life. Advances are also needed in osteobiologics and other grafting materials in order to improve fusion rates. Cell-based technologies, such as mesenchymal stem cells, with novel carrier materials may enable enhanced bone formation and fusion rates. ${ }^{24}$ Novel osteobiologics and enhancers of BMP-2 may also provide opportunities for increased fusion rates. ${ }^{24,28}$

Development of clinically significant PJK is likely multifactorial and may never be completely eliminated. Preplanned machine-bent rods may reduce junctional failures by helping to ensure that desired alignment corrections are achieved, including overall magnitudes of thoracic and lumbar curves, location of LL restoration (e.g., in the lower lumbar levels), and appropriate contouring of the proximal end of the rod. ${ }^{34,35,84}$ An overall better definition of individualized alignment objectives, beyond simple age-adjusted objectives, could markedly reduce PJK. ${ }^{32,36}$ In the future, more aggressive attention to bone optimization may also reduce junctional fractures. ${ }^{93}$ Ongoing advances in junctional tethers may also provide another approach to reduce PJK?

\section{Ongoing Evolution of Methodologies in Risk Stratification}

Tools for risk stratification, including age, American Society of Anesthesiologists class, Charlson Comorbidity Index, and subjective consensus opinion, have been historically crude and used as a means of limiting surgery to low-risk ASD patients. Although complications may be decreased by operating on more robust patients, ${ }^{71}$ more disabled patients often benefit the most from surgery. ${ }^{57,63,80}$ From a population standpoint, the greatest health improvement may come through optimization of care for the more disabled and frail patients, rather than simply confining care to low-risk groups. Recent data-intensive analyses have provided objective measures of procedure invasiveness and risk, as well as a standardized ASD frailty index, as steps toward an ongoing process to enable more meaningful risk stratification and preoperative optimization. ${ }^{44}$

\section{Predictive Analytics, Machine Learning, and Individualized Medicine}

As the availability of healthcare data is rapidly expanding and techniques for big data analysis are advancing, powerful machine learning techniques have been applied to reveal clinically useful information buried within vast amounts of data (Figs. 8 and 9). These techniques are only beginning to be applied to spine care. In the near future, predictive analytics has the potential to markedly reduce the uncertainties for all stakeholders in ASD care and revolutionize the overall treatment approach. Predictive models may facilitate surgeon decision making regarding operative versus nonoperative treatment and enable customized surgical planning to enhance durability and patient outcomes. ${ }^{1}$ Payers and hospitals may benefit from enhanced prediction of treatment costs and ability to predict catastrophic cost outliers (C.P. Ames et al., unpublished data, 2018).

Preoperative patient counseling may include individu- 
Smith et al.

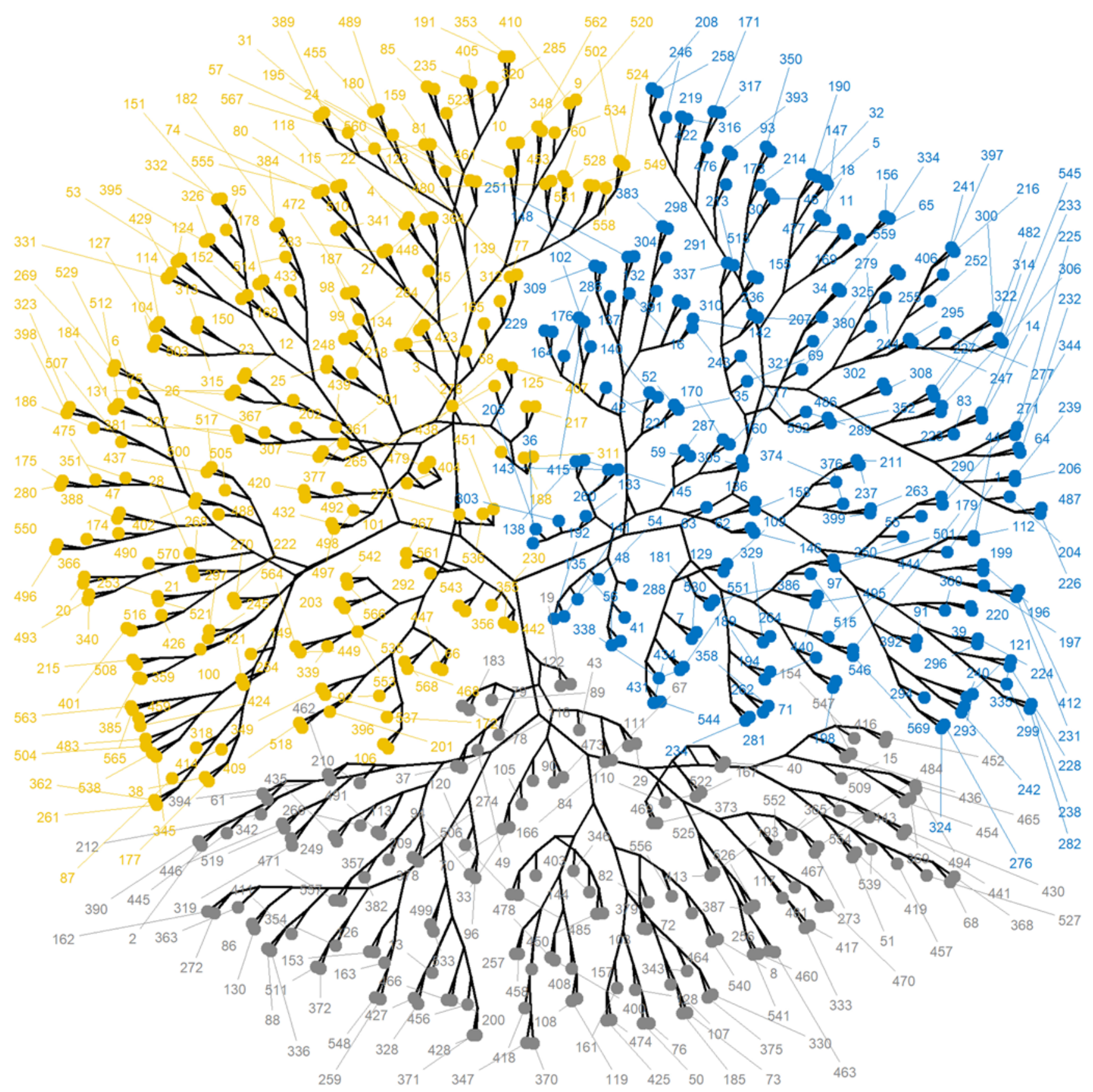

FIG. 8. Phylogenic dendrogram from application of unsupervised hierarchical clustering to 570 ASD patients treated surgically. Using an artificial intelligence-based clustering technique without a priori assumptions resulted in the definition of 3 distinct clusters of patient types. Each circle represents a different patient. Colors represent different patient clusters. Figure created using R programming language (https://www.r-project.org). Reproduced with permission from Ames CP, Smith JS, Pellisé F, Kelly M, Alanay A, Acaroĝlu E, et al: Artificial intelligence based hierarchical clustering of patient types and intervention categories in adult spinal deformity surgery: towards a new classification scheme that predicts quality and value. Spine (Phila Pa 1976) [epub ahead of print], 2019, https://journals.Iww.com/spinejournal/pages/default.aspx.

alized assessments of complication, reoperation, and readmission risks with surgery, as well as individualized predictions of outcomes metrics, patient-specific goals, and overall satisfaction. Early work through the ISSG has suggested that assessment of patient-specific goals through a patientgenerated index has greater responsiveness to treatment than standard PROMs. ${ }^{61}$ In addition, early ISSG-European Spine Study Group collaborative efforts have provided a glimpse of this ASD information revolution, including an online point-of-care risk outcomes calculator (Fig. 10) (C.P. Ames et al., unpublished data, 2018; and F. Pellisé et al., unpublished data, 2018). ${ }^{49,59,64-66}$ 


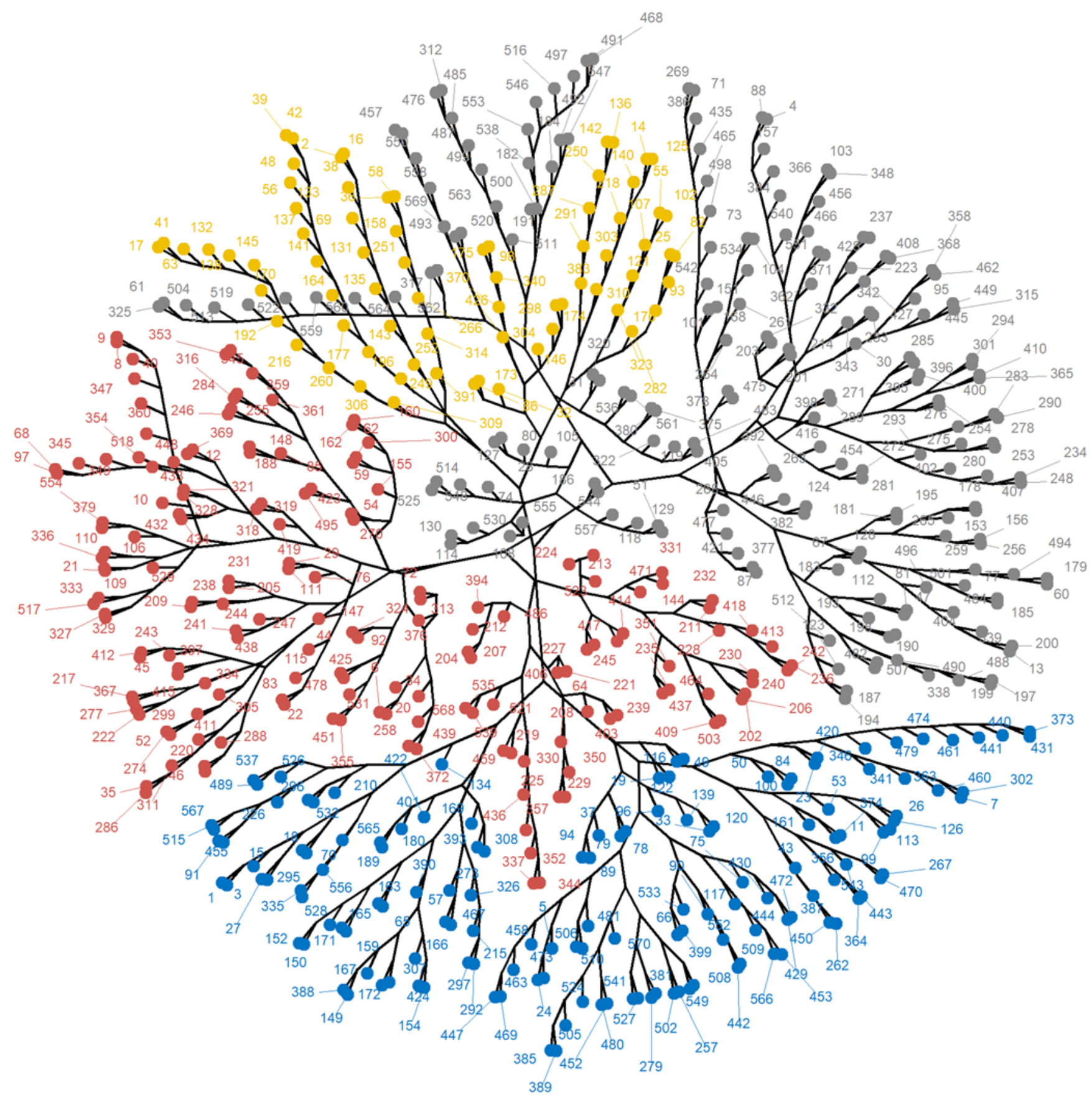

FIG. 9. Phylogenic dendrogram from application of unsupervised hierarchical clustering to 570 ASD patients treated surgically. Using an artificial intelligence-based clustering technique without a priori assumptions resulted in the definition of 4 distinct patterns of surgical treatments. Each circle represents a different patient, and colors represent different surgical treatment. Figure created using R programming language (https://www.r-project.org). Reproduced with permission from Ames CP, Smith JS, Pellisé F, Kelly $\mathrm{M}$, Alanay A, Acaroĝlu E, et al: Artificial intelligence based hierarchical clustering of patient types and intervention categories in adult spinal deformity surgery: towards a new classification scheme that predicts quality and value. Spine (Phila Pa 1976) [epub ahead of print], 2019, https://journals.Iww.com/spinejournal/pages/default.aspx.

\section{Advances in ASD Classification}

Historically, ASD has been classified based primarily on descriptive statistics and simplistic correlation-based systems ${ }^{69}$ but recent work suggests that there are many other impactful preoperative data points. However, the ability to segregate patient patterns manually based on hundreds of data points is beyond practical application for surgeons. Artificial intelligence-based unsupervised hierarchical clustering has recently been applied to a large ASD cohort to identify key patient type clusters and surgical treatment strategy clusters. ${ }^{1}$ The intersection of these patient-based and surgery-based clusters, with overlay of complication 
A

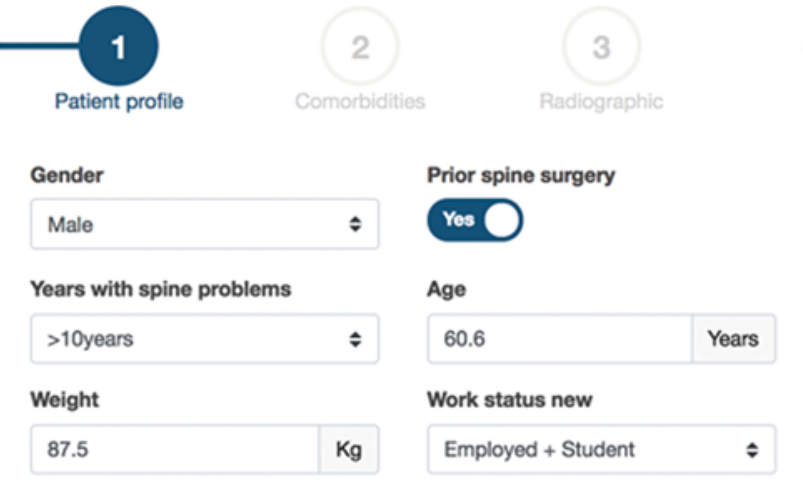
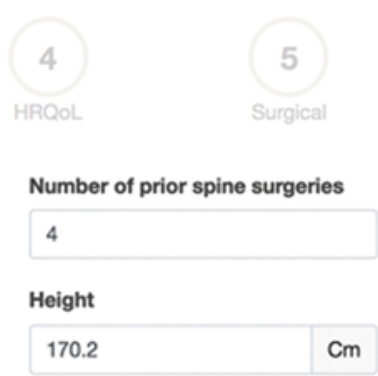

Level of physical labor in patient's job

Minimal

Save and exit Save and continue >

B

Major complications Reintervention Readmission

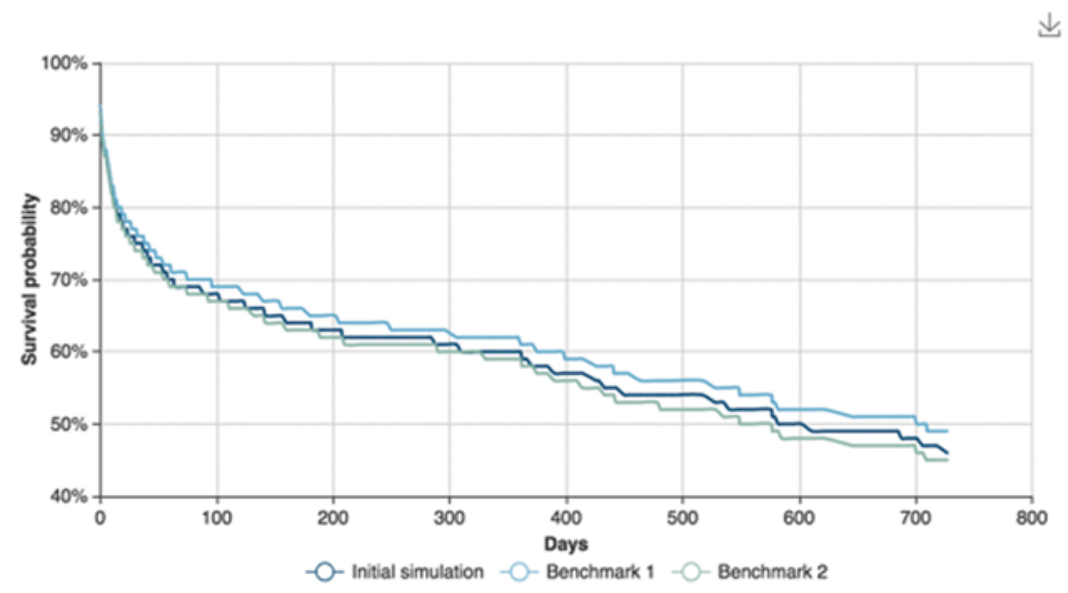

\begin{tabular}{|c|c|c|c|c|c|c|}
\hline Simulation & 3 days & 30 days & 60 days & 90 days & 1 year & 2 year \\
\hline Initial simulation & $87 \%$ & $75 \%$ & $70 \%$ & $68 \%$ & $59 \%$ & $47 \%$ \\
\hline Benchmark 1 & $88 \%$ & $77 \%$ & $71 \%$ & $70 \%$ & $61 \%$ & $50 \%$ \\
\hline Benchmark 2 & $87 \%$ & $74 \%$ & $69 \%$ & $68 \%$ & $58 \%$ & $46 \%$ \\
\hline
\end{tabular}

FIG. 10. Example images of an online point-of-care risk outcomes calculator interface and output for ASD surgery. A: Input data fields are grouped into categories, including patient profile (shown), comorbidities, radiographic, health-related quality of life (HRQoL) measures, and surgical. Output includes plots of individualized risk from time of surgery through the 2-year follow-up for occurrence of major complications. B: Similar plots are generated to reflect individualized risk from time of surgery through the 2-year follow-up for need for reoperation and need for hospital readmission (not shown). Output also includes individualized predictions of achieving a minimal clinically important difference for commonly used health-related quality of life assessment tools (not shown). Benchmarks can be added for reference. Figure created using R programming language (https://www.r-project.org). Figure is available in color online only.

rates, has produced a novel ASD classification that may facilitate treatment optimization of outcomes by identifying which treatment patterns yield optimal improvement with lowest risk.

\section{References}

1. Ames CP, Smith JS, Pellisé F, Kelly M, Alanay A, Acaroĝlu E, et al: Artificial intelligence based hierarchical clustering of patient types and intervention categories in adult spinal deformity surgery: towards a new classification scheme that predicts quality and value. Spine (Phila Pa 1976) [epub ahead of print], 2019

2. Ames CP, Smith JS, Scheer JK, Bess S, Bederman SS, Deviren $\mathrm{V}$, et al: Impact of spinopelvic alignment on decision making in deformity surgery in adults: a review. J Neurosurg Spine 16:547-564, 2012

3. Bess S, Harris JE, Turner AW, LaFage V, Smith JS, Shaffrey CI, et al: The effect of posterior polyester tethers on the biomechanics of proximal junctional kyphosis: a finite element analysis. J Neurosurg Spine 26:125-133, 2017 
4. Bess S, Line B, Fu KM, McCarthy I, Lafage V, Schwab F, et al: The health impact of symptomatic adult spinal deformity: comparison of deformity types to United States population norms and chronic diseases. Spine (Phila Pa 1976) 41:224233, 2016

5. Bridwell KH, Baldus C, Berven S, Edwards C II, Glassman $\mathrm{S}$, Hamill C, et al: Changes in radiographic and clinical outcomes with primary treatment adult spinal deformity surgeries from two years to three- to five-years follow-up. Spine (Phila Pa 1976) 35:1849-1854, 2010

6. Bridwell KH, Glassman S, Horton W, Shaffrey C, Schwab F, Zebala LP, et al: Does treatment (nonoperative and operative) improve the two-year quality of life in patients with adult symptomatic lumbar scoliosis: a prospective multicenter evidence-based medicine study. Spine (Phila Pa 1976) 34:2171-2178, 2009

7. Buell TJ, Buchholz AL, Quinn JC, Bess S, Line BG, Ames $\mathrm{CP}$, et al: A pilot study on posterior polyethylene tethers to prevent proximal junctional kyphosis after multilevel spinal instrumentation for adult spinal deformity. Oper Neurosurg (Hagerstown) 16:256-266, 2019

8. Buell TJ, Chen CJ, Quinn JC, Buchholz AL, Mazur MD, Mullin JP, et al: Alignment risk factors for proximal junctional kyphosis and the effect of lower thoracic junctional tethers for adult spinal deformity. World Neurosurg 121:e96-e103, 2019

9. Centers for Medicare \& Medicaid Services: National health expenditure data. CMS.gov (https://www.cms.gov/ResearchStatistics-Data-and-Systems/Statistics-Trends-and-Reports/ NationalHealthExpendData/index.html) [Accessed January 26, 2019]

10. Cheriyan T, Maier SP II, Bianco K, Slobodyanyuk K, Rattenni RN, Lafage V, et al: Efficacy of tranexamic acid on surgical bleeding in spine surgery: a meta-analysis. Spine J 15:752-761, 2015

11. Cotrel Y, Dubousset J, Guillaumat M: New universal instrumentation in spinal surgery. Clin Orthop Relat Res 227:1023, 1988

12. Dwyer AF, Newton NC, Sherwood AA: An anterior approach to scoliosis. A preliminary report. Clin Orthop Relat Res 62:192-202, 1969

13. Eastlack RK, Mundis GM Jr, Wang M, Mummaneni PV, Uribe J, Okonkwo D, et al: Is there a patient profile that characterizes a patient with adult spinal deformity as a candidate for minimally invasive surgery? Global Spine J 7:703-708, 2017

14. Ghasem A, Sharma A, Greif DN, Alam M, Maaieh MA: The arrival of robotics in spine surgery: a review of the literature. Spine (Phila Pa 1976) 43:1670-1677, 2018

15. Glassman SD, Bridwell K, Dimar JR, Horton W, Berven S, Schwab F: The impact of positive sagittal balance in adult spinal deformity. Spine (Phila Pa 1976) 30:2024-2029, 2005

16. Glassman SD, Carreon LY, Shaffrey CI, Polly DW, Ondra SL, Berven SH, et al: The costs and benefits of nonoperative management for adult scoliosis. Spine (Phila Pa 1976) 35:578-582, 2010

17. Gupta S, Eksi MS, Ames CP, Deviren V, Durbin-Johnson B, Smith JS, et al: A novel 4-rod technique offers potential to reduce rod breakage and pseudarthrosis in pedicle subtraction osteotomies for adult spinal deformity correction. Oper Neurosurg (Hagerstown) 14:449-456, 2018

18. Hamill CL, Lenke LG, Bridwell KH, Chapman MP, Blanke $\mathrm{K}$, Baldus $\mathrm{C}$ : The use of pedicle screw fixation to improve correction in the lumbar spine of patients with idiopathic scoliosis. Is it warranted? Spine (Phila Pa 1976) 21:1241-1249, 1996

19. Harrington PR: Treatment of scoliosis. Correction and internal fixation by spine instrumentation. J Bone Joint Surg Am 44-A:591-610, 1962
20. Hart RA, Hiratzka J, Kane MS, Lafage V, Klineberg E, Ames $\mathrm{CP}$, et al: Stiffness after pan-lumbar arthrodesis for adult spinal deformity does not significantly impact patient functional status or satisfaction irrespective of proximal endpoint. Spine (Phila Pa 1976) 42:1151-1157, 2017

21. Hazime FA, Baptista AF, de Freitas DG, Monteiro RL, Maretto RL, Hasue RH, et al: Treating low back pain with combined cerebral and peripheral electrical stimulation: a randomized, double-blind, factorial clinical trial. Eur J Pain 21:1132-1143, 2017

22. Hibbs RA: A report of fifty-nine cases of scoliosis treated by the fusion operation. J Bone Joint Surg Am 6:3-37, 1924

23. Hodaj H, Payen JF, Lefaucheur JP: Therapeutic impact of motor cortex rTMS in patients with chronic neuropathic pain even in the absence of an analgesic response. A case report. Neurophysiol Clin 48:303-308, 2018

24. Hsu WK, Goldstein CL, Shamji MF, Cho SK, Arnold PM, Fehlings MG, et al: Novel osteobiologics and biomaterials in the treatment of spinal disorders. Neurosurgery $\mathbf{8 0}$ (3S):S100-S107, 2017

25. Hung M, Hon SD, Franklin JD, Kendall RW, Lawrence BD, Neese A, et al: Psychometric properties of the PROMIS physical function item bank in patients with spinal disorders. Spine (Phila Pa 1976) 39:158-163, 2014

26. Hung M, Stuart A, Cheng C, Hon SD, Spiker R, Lawrence B, et al: Predicting the DRAM mZDI using the PROMIS anxiety and depression. Spine (Phila Pa 1976) 40:179-183, 2015

27. Januszewski J, Vivas AC, Uribe JS: Limitations and complications of minimally invasive spinal surgery in adult deformity. Ann Transl Med 6:109, 2018

28. Kanayama S, Kaito T, Kitaguchi K, Ishiguro H, Hashimoto $\mathrm{K}$, Chijimatsu R, et al: ONO-1301 Enhances in vitro osteoblast differentiation and in vivo bone formation induced by bone morphogenetic protein. Spine (Phila Pa 1976) 43:E616-E624, 2018

29. Kapural L, Peterson E, Provenzano DA, Staats P: Clinical evidence for spinal cord stimulation for failed back surgery syndrome (FBSS): systematic review. Spine (Phila Pa 1976) 42 (Suppl 14):S61-S66, 2017

30. Kelly MP, Lurie JD, Yanik EL, Shaffrey CI, Baldus CR, Boachie-Adjei O, et al: Surgery versus nonoperative care for adult symptomatic lumbar scoliosis. J Bone Joint Surg Am [in press], 2018

31. Kim HJ, Buchowski JM, Zebala LP, Dickson DD, Koester L, Bridwell KH: RhBMP-2 is superior to iliac crest bone graft for long fusions to the sacrum in adult spinal deformity: 4- to 14-year follow-up. Spine (Phila Pa 1976) 38:1209-1215, 2013

32. Lafage R, Bess S, Glassman S, Ames C, Burton D, Hart R, et al: Virtual modeling of postoperative alignment after adult spinal deformity surgery helps predict associations between compensatory spinopelvic alignment changes, overcorrection, and proximal junctional kyphosis. Spine (Phila Pa 1976) 42:E1119-E1125, 2017

33. Lafage R, Ferrero E, Henry JK, Challier V, Diebo B, Liabaud $\mathrm{B}$, et al: Validation of a new computer-assisted tool to measure spino-pelvic parameters. Spine J 15:2493-2502, 2015

34. Lafage R, Line BG, Gupta S, Liabaud B, Schwab F, Smith JS, et al: Orientation of the upper-most instrumented segment influences proximal junctional disease following adult spinal deformity surgery. Spine (Phila Pa 1976) 42:1570-1577, 2017

35. Lafage R, Obeid I, Liabaud B, Bess S, Burton D, Smith JS, et al: Location of correction within the lumbar spine impacts acute adjacent-segment kyphosis. J Neurosurg Spine [epub ahead of print October 1, 2018. DOI: 10.3171/2018.6.SPINE161468]

36. Lafage R, Schwab F, Glassman S, Bess S, Harris B, Sheer J, et al: Age-adjusted alignment goals have the potential to reduce PJK. Spine (Phila Pa 1976) 42:1275-1282, 2017 
37. Lagrone MO, Bradford DS, Moe JH, Lonstein JE, Winter RB, Ogilvie JW: Treatment of symptomatic flatback after spinal fusion. J Bone Joint Surg Am 70:569-580, 1988

38. Lau D, Funao H, Clark AJ, Nicholls F, Smith J, Bess S, et al: The clinical correlation of the Hart-ISSG Proximal Junctional Kyphosis Severity Scale with health-related quality-oflife outcomes and need for revision surgery. Spine (Phila Pa 1976) 41:213-223, 2016

39. Lenke LG, Fehlings MG, Shaffrey CI, Cheung KM, Carreon L, Dekutoski MB, et al: Neurologic outcomes of complex adult spinal deformity surgery: results of the prospective, multicenter Scoli-RISK-1 study. Spine (Phila Pa 1976) 41:204-212, 2016

40. Liu S, Diebo BG, Henry JK, Smith JS, Hostin R, Cunningham ME, et al: The benefit of nonoperative treatment for adult spinal deformity: identifying predictors for reaching a minimal clinically important difference. Spine J 16:210-218, 2016

41. Luque ER: Segmental spinal instrumentation for correction of scoliosis. Clin Orthop Relat Res (163):192-198, 1982

42. Madhavan K, Kolcun JPG, Chieng LO, Wang MY: Augmented-reality integrated robotics in neurosurgery: are we there yet? Neurosurg Focus 42(5):E3, 2017

43. McCarthy IM, Hostin RA, Ames CP, Kim HJ, Smith JS, Boachie-Adjei O, et al: Total hospital costs of surgical treatment for adult spinal deformity: an extended follow-up study. Spine J 14:2326-2333, 2014

44. Miller EK, Vila-Casademunt A, Neuman BJ, Sciubba DM, Kebaish KM, Smith JS, et al: External validation of the adult spinal deformity (ASD) frailty index (ASD-FI). Eur Spine J 27:2331-2338, 2018

45. Moe JH: Modern concepts of treatment of spinal deformities in children and adults. Clin Orthop Relat Res (150):137153,1980

46. Mummaneni PV, Park P, Fu KM, Wang MY, Nguyen S, Lafage $\mathrm{V}$, et al: Does minimally invasive percutaneous posterior instrumentation reduce risk of proximal junctional kyphosis in adult spinal deformity surgery? A propensity-matched cohort analysis. Neurosurgery 78:101-108, 2016

47. Mummaneni PV, Shaffrey CI, Lenke LG, Park P, Wang MY, La Marca F, et al: The minimally invasive spinal deformity surgery algorithm: a reproducible rational framework for decision making in minimally invasive spinal deformity surgery. Neurosurg Focus 36(5):E6, 2014

48. Naik BI, Pajewski TN, Bogdonoff DI, Zuo Z, Clark P, Terkawi AS, et al: Rotational thromboelastometry-guided blood product management in major spine surgery. J Neurosurg Spine 23:239-249, 2015

49. Oh T, Scheer JK, Smith JS, Hostin R, Robinson C, Gum JL, et al: Potential of predictive computer models for preoperative patient selection to enhance overall quality-adjusted life years gained at 2-year follow-up: a simulation in 234 patients with adult spinal deformity. Neurosurg Focus 43(6):E2, 2017

50. Overley SC, Cho SK, Mehta AI, Arnold PM: Navigation and robotics in spinal surgery: where are we now? Neurosurgery 80 (3S):S86-S99, 2017

51. Park P, Wang MY, Lafage V, Nguyen S, Ziewacz J, Okonkwo DO, et al: Comparison of two minimally invasive surgery strategies to treat adult spinal deformity. J Neurosurg Spine 22:374-380, 2015

52. Passias PG, Soroceanu A, Yang S, Schwab F, Ames C, Boniello A, et al: Predictors of revision surgical procedure excluding wound complications in adult spinal deformity and impact on patient-reported outcomes and satisfaction: a two-year follow-up. J Bone Joint Surg Am 98:536-543, 2016

53. Paul JC, Lonner BS, Vira S, Kaye ID, Errico TJ: Use of recombinant bone morphogenetic protein is associated with reduced risk of reoperation after spine fusion for adult spinal deformity. Spine (Phila Pa 1976) 41:E15-E21, 2016

54. Pellisé F, Vila-Casademunt A, Ferrer M, Domingo-Sàbat M, Bagó J, Pérez-Grueso FJ, et al: Impact on health related quality of life of adult spinal deformity (ASD) compared with other chronic conditions. Eur Spine J 24:3-11, 2015

55. Protopsaltis T, Schwab F, Bronsard N, Smith JS, Klineberg $\mathrm{E}$, Mundis $\mathrm{G}$, et al: The T1 pelvic angle, a novel radiographic measure of global sagittal deformity, accounts for both spinal inclination and pelvic tilt and correlates with health-related quality of life. J Bone Joint Surg Am 96:1631-1640, 2014

56. Raad M, Jain A, Huang M, Skolasky RL, Sciubba DM, Kebaish KM, et al: Validity and responsiveness of PROMIS in adult spinal deformity: the need for a self-image domain. Spine J 19:50-55, 2019

57. Reid DBC, Daniels AH, Ailon T, Miller E, Sciubba DM, Smith JS, et al: Frailty and health-related quality of life improvement following adult spinal deformity surgery. World Neurosurg 112: $548-e 554,2018$

58. Safaee MM, Osorio JA, Verma K, Bess S, Shaffrey CI, Smith JS, et al: Proximal junctional kyphosis prevention strategies: a video technique guide. Oper Neurosurg (Hagerstown) 13:581-585, 2017

59. Safaee MM, Scheer JK, Ailon T, Smith JS, Hart RA, Burton DC, et al: Predictive modeling of length of hospital stay following adult spinal deformity correction: analysis of 653 patients with an accuracy of $75 \%$ within 2 days. World Neurosurg 115:e422-e427, 2018

60. Scalise J, Jacofsky D: Payor reform opportunities for spine surgery: part III: population health programs and converging strategies. Clin Spine Surg 31:347-350, 2018

61. Scheer JK, Keefe M, Lafage V, Kelly MP, Bess S, Burton DC, et al: Importance of patient-reported individualized goals when assessing outcomes for adult spinal deformity (ASD): initial experience with a Patient Generated Index (PGI). Spine J 17:1397-1405, 2017

62. Scheer JK, Lafage R, Schwab FJ, Liabaud B, Smith JS, Mundis GM, et al: Under correction of sagittal deformities based on age-adjusted alignment thresholds leads to worse healthrelated quality of life whereas over correction provides no additional benefit. Spine (Phila Pa 1976) 43:388-393, 2018

63. Scheer JK, Lafage V, Smith JS, Deviren V, Hostin R, McCarthy IM, et al: Impact of age on the likelihood of reaching a minimum clinically important difference in 374 three-column spinal osteotomies: clinical article. J Neurosurg Spine 20:306-312, 2014

64. Scheer JK, Osorio JA, Smith JS, Schwab F, Hart RA, Hostin $\mathrm{R}$, et al: Development of a preoperative predictive model for reaching the Oswestry Disability Index minimal clinically important difference for adult spinal deformity patients. Spine Deform 6:593-599, 2018

65. Scheer JK, Osorio JA, Smith JS, Schwab F, Lafage V, Hart RA, et al: Development of validated computer-based preoperative predictive model for proximal junction failure (PJF) or clinically significant PJK with $86 \%$ accuracy based on 510 ASD patients with 2-year follow-up. Spine (Phila Pa 1976) 41:E1328-E1335, 2016

66. Scheer JK, Smith JS, Schwab F, Lafage V, Shaffrey CI, Bess $\mathrm{S}$, et al: Development of a preoperative predictive model for major complications following adult spinal deformity surgery. J Neurosurg Spine 26:736-743, 2017

67. Schwab F, Blondel B, Chay E, Demakakos J, Lenke L, Tropiano P, et al: The comprehensive anatomical spinal osteotomy classification. Neurosurgery 76 (Suppl 1):S33-S41, 2015

68. Schwab F, Dubey A, Gamez L, El Fegoun AB, Hwang K, Pagala M, et al: Adult scoliosis: prevalence, SF-36, and nutritional parameters in an elderly volunteer population. Spine (Phila Pa 1976) 30:1082-1085, 2005

69. Schwab F, Ungar B, Blondel B, Buchowski J, Coe J, Deinlein 
D, et al: Scoliosis Research Society-Schwab adult spinal deformity classification: a validation study. Spine (Phila Pa 1976) 37:1077-1082, 2012

70. Schwab FJ, Blondel B, Bess S, Hostin R, Shaffrey CI, Smith JS, et al: Radiographical spinopelvic parameters and disability in the setting of adult spinal deformity: a prospective multicenter analysis. Spine (Phila Pa 1976) 38:E803-E812, 2013

71. Sethi RK, Pong RP, Leveque JC, Dean TC, Olivar SJ, Rupp SM: The Seattle Spine Team approach to adult deformity surgery: a systems-based approach to perioperative care and subsequent reduction in perioperative complication rates. Spine Deform 2:95-103, 2014

72. Shin BJ, James AR, Njoku IU, Härtl R: Pedicle screw navigation: a systematic review and meta-analysis of perforation risk for computer-navigated versus freehand insertion. J Neurosurg Spine 17:113-122, 2012

73. Slobodyanyuk K, Poorman CE, Smith JS, Protopsaltis TS, Hostin R, Bess S, et al: Clinical improvement through nonoperative treatment of adult spinal deformity: who is likely to benefit? Neurosurg Focus 36(5):E2, 2014

74. Smith JS, Klineberg E, Lafage V, Shaffrey CI, Schwab F, Lafage R, et al: Prospective multicenter assessment of perioperative and minimum 2-year postoperative complication rates associated with adult spinal deformity surgery. J Neurosurg Spine 25:1-14, 2016

75. Smith JS, Klineberg E, Schwab F, Shaffrey CI, Moal B Ames CP, et al: Change in classification grade by the SRSSchwab Adult Spinal Deformity Classification predicts impact on health-related quality of life measures: prospective analysis of operative and nonoperative treatment. Spine (Phila Pa 1976) 38:1663-1671, 2013

76. Smith JS, Lafage V, Shaffrey CI, Schwab F, Lafage R, Hostin R, et al: Outcomes of operative and nonoperative treatment for adult spinal deformity: a prospective, multicenter, propensity-matched cohort assessment with minimum 2-year follow-up. Neurosurgery 78:851-861, 2016

77. Smith JS, Shaffrey CI, Berven S, Glassman S, Hamill C, Horton W, et al: Improvement of back pain with operative and nonoperative treatment in adults with scoliosis. Neurosurgery 65:86-94, 2009

78. Smith JS, Shaffrey CI, Berven S, Glassman S, Hamill C, Horton W, et al: Operative versus nonoperative treatment of leg pain in adults with scoliosis: a retrospective review of a prospective multicenter database with two-year follow-up. Spine (Phila Pa 1976) 34:1693-1698, 2009

79. Smith JS, Shaffrey CI, Bess S, Shamji MF, Brodke D, Lenke LG, et al: Recent and emerging advances in spinal deformity. Neurosurgery 80 (3S):S70-S85, 2017

80. Smith JS, Shaffrey CI, Glassman SD, Berven SH, Schwab FJ, Hamill CL, et al: Risk-benefit assessment of surgery for adult scoliosis: an analysis based on patient age. Spine (Phila Pa 1976) 36:817-824, 2011

81. Smith JS, Shaffrey CI, Lafage V, Schwab F, Scheer JK, Protopsaltis T, et al: Comparison of best versus worst clinical outcomes for adult spinal deformity surgery: a retrospective review of a prospectively collected, multicenter database with 2-year follow-up. J Neurosurg Spine 23:349-359, 2015

82. Smith JS, Shaffrey E, Klineberg E, Shaffrey CI, Lafage V, Schwab FJ, et al: Prospective multicenter assessment of risk factors for rod fracture following surgery for adult spinal deformity. J Neurosurg Spine 21:994-1003, 2014

83. Smith JS, Singh M, Klineberg E, Shaffrey CI, Lafage V, Schwab FJ, et al: Surgical treatment of pathological loss of lumbar lordosis (flatback) in patients with normal sagittal vertical axis achieves similar clinical improvement as surgical treatment of elevated sagittal vertical axis: clinical article. J Neurosurg Spine 21:160-170, 2014

84. Solla F, Barrey CY, Burger E, Kleck CJ, Fière V: Patient- specific rods for surgical correction of sagittal imbalance in adults: technical aspects and preliminary results. Clin Spine Surg [epub ahead of print], 2018

85. Tang JA, Leasure JM, Smith JS, Buckley JM, Kondrashov D, Ames CP: Effect of severity of rod contour on posterior rod failure in the setting of lumbar pedicle subtraction osteotomy (PSO): a biomechanical study. Neurosurgery 72:276-283, 2013

86. Teles AR, Mattei TA, Righesso O, Falavigna A: Effectiveness of operative and nonoperative care for adult spinal deformity: systematic review of the literature. Global Spine J 7:170 178, 2017

87. Theologis AA, Demirkiran G, Callahan M, Pekmezci M, Ames C, Deviren V: Local intrawound vancomycin powder decreases the risk of surgical site infections in complex adult deformity reconstruction: a cost analysis. Spine (Phila Pa 1976) 39:1875-1880, 2014

88. Urbanski W, Jurasz W, Wolanczyk M, Kulej M, Morasiewicz P, Dragan SL, et al: Increased radiation but no benefits in pedicle screw accuracy with navigation versus a freehand technique in scoliosis surgery. Clin Orthop Relat Res 476:1020-1027, 2018

89. Uribe JS, Schwab F, Mundis GM Jr, Xu DS, Januszewski J, Kanter AS, et al: The comprehensive anatomical spinal osteotomy and anterior column realignment classification. J Neurosurg Spine 29:565-575, 2018

90. Wang MY, Bordon G: Mini-open pedicle subtraction osteotomy as a treatment for severe adult spinal deformities: case series with initial clinical and radiographic outcomes. J Neurosurg Spine 24:769-776, 2016

91. Wang MY, Mummaneni PV, Fu KM, Anand N, Okonkwo DO, Kanter AS, et al: Less invasive surgery for treating adult spinal deformities: ceiling effects for deformity correction with 3 different techniques. Neurosurg Focus 36(5):E12, 2014

92. Wilber RG, Thompson GH, Shaffer JW, Brown RH, Nash CL Jr: Postoperative neurological deficits in segmental spinal instrumentation. A study using spinal cord monitoring. J Bone Joint Surg Am 66:1178-1187, 1984

93. Yagi M, Ohne H, Konomi T, Fujiyoshi K, Kaneko S, Komiyama $\mathrm{T}$, et al: Teriparatide improves volumetric bone mineral density and fine bone structure in the UIV+1 vertebra, and reduces bone failure type PJK after surgery for adult spinal deformity. Osteoporos Int 27:3495-3502, 2016

94. Yao R, Tan T, Tee JW, Street J: Prophylaxis of surgical site infection in adult spine surgery: a systematic review. J Clin Neurosci 52:5-25, 2018

95. Zielke K, Stunkat R, Beaujean F: [Ventrale derotationsspondylodesis (author's transl).] Arch Orthop Unfallchir 85:257-277, 1976 (Ger)

\section{Disclosures}

Dr. Smith: consultant for Zimmer Biomet, NuVasive, Cerapedics, AlloSource, and K2M; teaching honoraria from Zimmer Biomet, NuVasive, and K2M; royalties from Zimmer Biomet; research grants from ISSG and DePuy Synthes; and fellowship funding from AOSpine and NREF. Dr. Shaffrey: consultant for Medtronic, NuVasive, Zimmer Biomet, K2M, Stryker, and In Vivo; royalties from Medtronic, NuVasive, and Zimmer Biomet; stock holder with NuVasive; patent holder with NuVasive; grants from NIH, Department of Defense, ISSG, DePuy Synthes, and AOSpine. Dr. Ames: employee of UCSF; consultant for DePuy Synthes, Medtronic, Stryker, Zimmer Biomet, Medicrea, and K2M; royalties from Zimmer Biomet, Stryker, DePuy Synthes, NuVasive, Next Orthosurgical, K2M, and Medicrea; patents with Fish \& Richardson, PC; research support from Titan, Spine, DePuy Synthes, and ISSG; editorial board of Operative Neurosurgery; exec- 
utive committee of ISSG; director of Global Spine Analytics. Dr. Lenke: consultant for Medtronic and EOS Technologies; royalties from Medtronic and Quality Medical Publishing; research grants from AOSpine, Scoliosis Research Society, EOS Technologies, Harms Study Group/Setting Scoliosis Straight Foundation, and Fox Family Foundation; deputy editor for Spine Deformity; editorial board of Journal of Neurosurgery Spine; reviewer for Spine, JBJS, Journal of Pediatric Orthopedics; and board of directors for OREF and Global Spine Outreach.

\section{Author Contributions}

Conception and design: Smith, Shaffrey, Ames, Lenke. Acquisition of data: Smith. Analysis and interpretation of data: Smith.
Drafting the article: Smith, Shaffrey, Ames, Lenke. Critically revising the article: all authors. Reviewed submitted version of manuscript: all authors. Approved the final version of the manuscript on behalf of all authors: Smith. Administrative/technical/ material support: Shaffrey. Study supervision: Shaffrey.

\section{Correspondence}

Justin S. Smith: University of Virginia Health System, Charlottesville, VA.jss7f@virginia.edu. 